\title{
THE MARKETING VALUE OF SUSTAINABILITY IN EUROPE, AS SEEN BY TOURISM DEVELOPERS - AN EXPLORATORY APPROACH TO PORTUGUESE TOURISM PRECINCTS
}

\author{
JOAO-MANUEL CARVALHO \\ University of Lisbon, Lisbon School of Architecture, CIAUD, Portugal.
}

\begin{abstract}
Tourism precincts have a very relevant territorial presence in areas with the most valued landscape features, both scenic and ecological lato sensu. The rationale of their development is allocating a business value to those very same features. The design of territorial occupation tends however to fit best practices and therefore sustainability is duly taken into account. But, do developers value it in their marketing documents? Is sustainability already a settled stance which needs not to be stated, or is it worth while mentioning by developers because it is an end-users' choice criterion? By resorting to European Union tourism sustainability categories and using them to assess the sustainability discourse in the marketing statements of Portuguese recent tourism developments (precincts), we approach the answers to the abovementioned questions. The result seems to be a subdued relevance of sustainability for marketing purposes. The derived risk might be the stagnation on the path towards a more comprehensive sustainability if the latter doesn't work as a marketing differentiation tool.

Keywords: marketing, sustainability, territory occupation, tourism precinct.
\end{abstract}

\section{INTRODUCTION}

Tourism, as an economic activity, is a territory-associated economic development opportunity. It occupies the areas that benefit from Nature's endowments. Presently, whenever tourism developments or redevelopments take place in those areas, there is a consensual awareness that natural resources may not be depleted and past errors on this issue must be compensated. This corresponds to a sustainability culture.

However, not all tourism ventures are able to fully adhere to this culture, because they are stuck either in layouts or in construction systems of a previous era, too expensive to turn around. This means that the tourism ventures that are able to state their sustainability should have a marketing advantage towards some of the stock (though a part of this occupies the prime sites, since having "arrived" first).

We may question if the more sustainable tourism developments bet on sustainability as a marketing tool or take it as a mere compulsory compliance with permit norms. In the former case we should expect to find sustainability statements in the marketing documents. In the other case further progress towards sustainability in tourism developments will depend on norms issued by the community (i.e., the State).

\section{AIM AND METHODOLOGY}

The main research concern of this exploratory study is to find out hints on the importance assigned to sustainability for the marketing purposes of the tourism developments. The methodological steps for the purpose consist of (i) identifying analytical categories that may provide for a "grid" to approach marketing statements on tourism sustainability at the internet sites of chosen tourism precincts, (ii) choosing a sample of recent (with the assumption that the more recent the more sustainability-minded) tourism developments for the purpose of 
experimenting on the approach, (iii) counting the mentions on the previously selected sustainability categories/criteria found at each internet site, (iv) weighting the categories/criteria to take into account that the mere occurrence of the sustainability mention might not be enough to assess the marketing importance assigned to sustainability issues and (v) score the marketing importance of sustainability statements once the relative importance of the categories/criteria has been taken into account. The sample case studies are Portuguese tourism precincts ("resorts" in the Portuguese law) [1].

\section{SUSTAINABILITY CATEGORIES AND CRITERIA}

Giving the notion of sustainability an operational character, which includes its targeting a specific subject, is a demanding task [2]. Hereafter we will respond to this task by using a European Union (EU) work on the sustainability of tourism destinations [3].

The EU study provides four basic categories for the analysis of the tourism destination sustainability; those categories may be represented by criteria, some of them also provided by the EU study, others of our own choice.

The four categories on sustainability and the related criteria are, for the purpose of our study, introduced in Table 1.

Table 1: EU categories to assess tourism sustainability

\section{Destination Management:}

Regional sustainability features

Pristine character of the destination landscape

Role of soft mobility

Regional heritage conservation

Regional sustainability norms for tourism

\section{Economic Value:}

Procurement in local employment

Procurement in regional production

Relationship with regional social facilities (e.g., health)

\section{Societal and Cultural Impact:}

On site heritage as a feature of the tourism product

Tourism product associated to local traditions

Tourism buildings recreate local architecture

Tourism building interiors integrate local artistry

Tourism venture includes professional training

\section{Environmental Impact:}

Sustainability state of the art on energy efficiency

Sustainability state of the art on water management

Sustainability state of the art on waste management

Ecological landscaping (e.g., local species)

Ecological footprint 
We assume that it is a marketing plus for developers to state the sustainability of their tourism precincts which they could do through the criteria at Table 1. For instance, stating that the precinct is "state of the art" on water management is clearly a plus; therefore the developers should be concerned with stating it for marketing purposes. This is how we assume all the selected criteria work.

When developers don't mention those criteria for marketing purposes it is either because the criteria don't correspond to installed features or because they don't think it is worthwhile mentioning those criteria (which might be a reason not to have them installed).

These criteria are further on used to count the marketing mentions on sustainability of a selected sample of tourism developments/precincts. As the criteria may easily be envisaged as not having equal relevance, a second stage with weighted criteria is introduced into the analysis.

The weights have been obtained through asking 50 persons to allocate 10 score points among the criteria, their final weight being the proportion assigned to each criterion (Table 2). The rationale of the allocation relied on the following question: "Were you a customer to a tourism precinct that states its sustainability, what are the stated sustainability features that you would rate as more significant?"

For the purpose of weight allocation some examples had to be given in order to make the criteria more intelligible, e.g., "Regional sustainability features" refers to installed sustainability features in the region, while "Regional sustainability norms for tourism" refers to the regional sustainability aims as expressed in the legal framework and "Pristine character of the destination landscape" refers to "unspoiled" landscape features that may not be the outcome of sustainability concerns but a residual circumstance; "Relationship with regional

Table 2: Criteria weights

\begin{tabular}{lr}
\hline & Weight \\
\hline 1. Regional sustainability features & 5.2 \\
2. Pristine character of the destination landscape & 4.7 \\
3. Role of soft mobility & 4.5 \\
4. Regional heritage conservation & 5.7 \\
5. Regional sustainability norms for tourism & 2.7 \\
6. Procurement in local employment & 5.2 \\
7. Procurement in regional production & 6.9 \\
8. Relationship with regional social facilities (e.g., health) & 8.3 \\
9. On site heritage as a feature of the tourism product & 1.4 \\
10. Tourism product associated to local traditions & 3.3 \\
11. Tourism buildings recreate local architecture & 5.9 \\
12. Tourism building interiors integrate local artistry & 2.6 \\
13. Tourism venture includes professional training & 1.8 \\
14. Sustainability state of the art on energy efficiency & 10.2 \\
15. Sustainability state of the art on water management & 6.8 \\
16. Sustainability state of the art on waste management & 4.6 \\
17. Ecological landscaping (e.g., local species) & 9.4 \\
18. Ecological footprint & 10.8 \\
\hline
\end{tabular}


social facilities" (which is in fact a sub-category in the EU document) refers to protocoltype agreements the tourism developers may have settled with local social units for assisting their customers or employees.

Statements on the measurement of the ecological footprint, on energy efficiency, on ecological landscaping, on quantitative economic impact on local employment and on association to local facilities have deserved the higher ratings, meaning that developers would benefit most of announcing these features for marketing purposes. On the opposite, norms for tourism sustainability, soft mobility, integration into the tourism product of onsite heritage or local traditions have been less rated.

\section{THE TOURISM PRECINCTS}

The chosen sample (Table 3) consists of some of the most recent Portuguese tourism developments of the precinct type ("resorts" in the Portuguese tourism laws). The sample includes very disparate sizes (i.e., homogeneity on marketing period prevails over size homogeneity), as we assume that every tourism resort would gain from announcing advanced sustainability features, whatever its size.

The labels (i.e., "Type") were introduced ad hoc to provide for an abbreviated description of the resort features. "Mountain" stands for non-coastal regions with a mountainous landscape (it does not stand for skiing resort), the distinction between "Coastal" and "Beach" resides on the direct walking access to the beach of the latter (location adjacent to the beach with a proper beach concession) and "Residential" means that tourism premises are marginal to the development business (i.e., though leisure and sports facilities are supposed to exist, residential tourism or permanent residence are the core of the business). "Type" is however assumed not to influence the role that sustainability statements might have for marketing purposes, though it might influence the weight of the sustainability components (e.g., "Mountain" might allow for stating Nature conservation as a regional feature that could substitute a weaker stance of the tourism resort on environmental issues).

Table 3: The tourism precincts sample

\begin{tabular}{lll}
\hline Name & Type & Area (ha) \\
\hline Quinta das Lameiras & Mountain & 25 \\
Matas de Sesimbra & Coastal/Golf & 5.260 \\
Herdade da Comporta & Coastal/Golf & 916 \\
Vale do Freixo & Mountain/Golf & 381 \\
Ombria Resort & Mountain/Golf & 145 \\
Vilamoura Lakes & Marina resort & 168 \\
Herdade de Monteverde & Golf/Residential & 102 \\
West Cliffs & Coastal /Golf & 49 \\
W Algarve & Costal/Residential & 25 \\
L'Orangerie (Vilam.) & Coastal/Golf & 7 \\
Tróia Resort & Coastal/Golf & 440 \\
Pestana Tróia Eco & Beach & 100 \\
White Shell & Beach & 4 \\
\hline
\end{tabular}




\section{ANALYSIS}

The first step of the analysis relies on counting the sustainability statements ("occurrences") that are found in the commercial internet site of the resort, using the EU categories and associated criteria. The main evidence we can outline (Table 4) is that sustainability statements for marketing purposes are not common (only 1 resort reaches $50 \%$ of the maximum possible statements, two of them have none of the latter and the remaining resorts don't overcome 30\%).

The EU category Destination Management has a number of occurrences significantly higher than the others, which is very similar among them. This may hint at the sustainability commercial image of the tourism precinct mostly depending on the region image, which could fit the low number of occurrences for resort-specific sustainability statements (i.e., though the resort could state its own features and use the destination ones as a reinforcement of the former, it seems that the latter may dispense with the former); it also fits with the region pristine landscape being the criterion with the highest number of occurrences within the Destination Management category.

The criterion Ecological Footprint (within the category Environmental Impact) has a number of occurrences slightly above the average; we may conjecture that it is because it is a comprehensive statement (which may work like a "disclaimer") or because it is seen by developers as an easy way to communicate the resort sustainability, since it fits the marketing target' own idea of how sustainability should be addressed.

Table 4: Number of occurrences (non-weighted)

\begin{tabular}{|c|c|c|c|c|c|c|}
\hline & $\begin{array}{l}\text { Ocurrences } \\
\text { non-weighted }\end{array}$ & $\begin{array}{l}\text { Destination } \\
\text { manage- } \\
\text { ment }\end{array}$ & $\begin{array}{l}\text { Economic } \\
\text { Value }\end{array}$ & $\begin{array}{l}\text { Societal } \\
\text { and } \\
\text { cultural } \\
\text { imp. }\end{array}$ & $\begin{array}{l}\text { Environ- } \\
\text { mental } \\
\text { impact }\end{array}$ & $\begin{array}{l}\text { TOTAL } \\
/ 18\end{array}$ \\
\hline Q. das Lameiras & Mountain & 1 & 1 & 2 & 1 & 0.3 \\
\hline M. de Sesimbra & Coastal/Golf & 0 & 3 & 0 & 3 & 0.3 \\
\hline H. da Comporta & Coastal/Golf & 1 & 0 & 2 & 0 & 0.2 \\
\hline Vale do Freixo & Mountain/Golf & 2 & 0 & 0 & 0 & 0.1 \\
\hline Q. da Ombria & Mountain/Golf & 1 & 3 & 2 & 3 & 0.5 \\
\hline Vilamoura Lakes & Marina resort & 1 & 0 & 1 & 0 & 0.1 \\
\hline $\begin{array}{l}\text { H. de } \\
\text { Monteverde }\end{array}$ & $\begin{array}{l}\text { Golf/residen- } \\
\text { tial }\end{array}$ & 1 & 0 & 0 & 0 & 0.1 \\
\hline West Cliffs & Coastal/Golf & 3 & 0 & 0 & 0 & 0.2 \\
\hline W Algarve & $\begin{array}{l}\text { Coastal/resi- } \\
\text { dential }\end{array}$ & 0 & 0 & 0 & 0 & 0.0 \\
\hline $\begin{array}{l}\text { L'Orangerie } \\
\text { Vilam. }\end{array}$ & Coastal/Golf & 1 & 0 & 1 & 0 & 0.1 \\
\hline Tróia Resort & Coastal/Golf & 2 & 0 & 1 & 0 & 0.2 \\
\hline $\begin{array}{l}\text { Pestana Tróia } \\
\text { Eco }\end{array}$ & Beach & 2 & 1 & 0 & 1 & 0.2 \\
\hline White Shell & Beach & 0 & 0 & 0 & 0 & 0.0 \\
\hline TOTAL & & 15 & 8 & 9 & 8 & 2.2 \\
\hline
\end{tabular}


Table 5: Number of occurrences (weighted)

\begin{tabular}{|c|c|c|c|c|c|c|}
\hline & $\begin{array}{l}\text { Ocurrences } \\
\text { weighted }\end{array}$ & $\begin{array}{l}\text { Destina- } \\
\text { tion } \\
\text { Manage- } \\
\text { ment }\end{array}$ & $\begin{array}{l}\text { Eco- } \\
\text { nomic } \\
\text { Value }\end{array}$ & $\begin{array}{l}\text { Societal } \\
\text { and } \\
\text { Cultural } \\
\text { Imp. }\end{array}$ & $\begin{array}{l}\text { Environ- } \\
\text { mental } \\
\text { Impact }\end{array}$ & TOTAL \\
\hline Q. das Lameiras & Mountain & 4.7 & 6.9 & 5.9 & 9.4 & 26.9 \\
\hline M. de Sesimbra & Coastal/Golf & 0 & 0 & 0 & 37.3 & 37.3 \\
\hline H. da Comporta & Coastal/Golf & 4.7 & 0 & 4.7 & 0 & 9.4 \\
\hline Vale do Freixo & Mountain/Golf & 10.4 & 6.9 & 0 & 0 & 17.3 \\
\hline Q. da Ombria & Mountain/Golf & 4.7 & 0 & 9.2 & 37.3 & 51.2 \\
\hline Vilamoura Lakes & Marina resort & 4.5 & 8.3 & 1.4 & 0 & 14.2 \\
\hline H. de Monteverde & Golf/residential & 4.7 & 0 & 0 & 0 & 4.7 \\
\hline West Cliffs & Coastal/Golf & 15.6 & 0 & 0 & 0 & 15.6 \\
\hline W Algarve & Coastal/residential & 0 & 0 & 0 & 0 & 0.0 \\
\hline $\begin{array}{l}\text { L'Orangerie } \\
\text { Vilam. }\end{array}$ & Coastal/Golf & 4.5 & 8.3 & 5.9 & 0 & 18.7 \\
\hline Tróia Resort & Coastal/Golf & 9.9 & 0 & 1.4 & 0 & 11.3 \\
\hline Pestana Tróia Eco & Beach & 9.9 & 8.3 & 0 & 10.8 & 29.0 \\
\hline White Shell & Beach & 0 & 0 & 0 & 21 & 21.0 \\
\hline TOTAL & & 73.6 & 38.7 & 28.5 & 115.8 & 256.6 \\
\hline
\end{tabular}

The introduction of the criteria weights (Table 5) points at sustainability statements for marketing purposes, though infrequent, being selected according to their importance, since we now have five detached tourism precincts against only one before weighting.

The Destination Management category becomes second after weighting, as Environmental Impact gets the highest score. Economic Value and Societal and Cultural Impact emerge as subdued categories.

The high score of the Environmental Impact category mostly derives from the weights assigned to the criteria Energy Efficiency, Ecological Landscaping and Ecological Footprint, all of them corresponding to much publicized issues within the environmental concerns culture and therefore easily apprehended by the marketing target.

\section{CONCLUSIONS}

The tourism developments of the typology we are addressing (tourism precincts, or "resorts" in the Portuguese law) are the outcome of design issues at several levels - masterplan level (having in mind the landscape abilities for sheltering large leisure items - e.g., golf courses - and mostly for sheltering housing units since real estate is an anchor component of these tourism developments), hotel level (finding out positive differentiations that provide for a good competitive stance), small neighborhoods level (in search for internal diversity) and housing units level (as the sales proceeds' focus of the tourism development business). 
Sustainability is presently a good practices issue and therefore it surely is duly dealt with in the masterplans and construction features of the tourism developments we are addressing (i.e., tourism precincts). We can however hypothesize that those good practices are mostly a form of compliance with permit norms whenever they are not seen as a marketing trump. If envisaged like a marketing trump, they would be announced on the internet sites of the tourism precincts.

Since the core business of these tourism developments is real estate, we should expect once we assume that sustainability that goes beyond the permit requirements is a marketing tool for the purpose of sales to end-users and also to a possible real estate investor that buys the hotel buildings, all of them with long-term concerns - the developers to emphasize the optional sustainability features of their ventures as a procedure for sales enhancement.

The evidence withdrawn from a sample of Portuguese cases hints at the compliance scenario having a main role, when compared with the marketing scenario - i.e., sustainability is not often made explicit on marketing statements of the tourism developments, though it had to attend to compulsory permit rules on sustainability. This conclusion derives from the low number of statements on sustainability detected at the internet sites of the tourism developments.

The marketing relevance of the perceivable sustainability of the tourism region where the development took place seems to overcome the internal sustainability relevance when it comes to using sustainability as a marketing tool, hinting at some free riddance that dispenses the development from featuring advanced sustainability. Among the rare mentions to sustainability the mentions to "destination management" features have an above-the-average incidence.

When the marketing value of each stated sustainability item (i.e., criteria) is taken into account, through assigned weights, the role of the region becomes second, since the issues directly associated to environmental impact emerge as more important. This evidences that whenever sustainability is made explicit on marketing statements it is on issues that are taken as common - even if fuzzy - knowledge (e.g., energy efficiency, ecological landscaping or ecological footprint) and which are not detailed; innovation on sustainability concerns is absent. The mentioned issues may however be assumed by the developers as efficient for marketing purposes and may have been selected accordingly, meaning that the developers' perspective on their marketing target (i.e., mostly real estate buyers of second homes or real estate investors) may be one of "traditional" views on sustainability.

Such a stance for recent tourism developments allows for admitting that sustainability statements are presently not important on the commercial strategy of tourism precinct developers. Those statements are neither frequent nor very much worked upon. The low importance for sales enhancement given to sustainability statements is associated to sustainability installed features that do not go beyond what is required by planning and building permits.

The tourism ventures we addressed are large landscape transformation operations which business target is long-term minded (as are all real estate buyers). If sustainability does not advance voluntarily within this profile of operations, the same will probably happen in tourism ventures of a smaller scale and mostly oriented to hotel operation.

The conclusions of the experiment therefore alert for the need of introducing additional permit norms on sustainability whenever the aim is to deepen the latter, since apparently the market would not be an enough stimulus for the purpose.

Though this preliminary outcome derives from an exploratory approach based on the use of analytic categories, criteria and weighting that can be further discussed and fine-tuned, the 
direction of the conclusions seems quite settled and can also be illustrated by the fact that only one of our sample elements has in its internet site a window named "sustainability", all the others' marketing statements referring exclusively to masterplan principles, leisure features, scenic values and real estate differentiation. Sustainability is, in these cases, a mere permit requirement. A further research question could therefore be "what sustainability requirements should be appended to planning and building permits in order to make high impact landscape operations, that target affluent market segments, advanced sustainability providers?"

\section{REFERENCES}

[1] Carvalho, J-M. \& Martins, C., Large tourism precints in South Western Europe genesis, evolution and territorial impact. International Journal of Sustainable Development and Planning, XI(3), pp. 285-294, 2016. https://doi.org/10.2495/sdp-v11-n3-285-294

[2] Carvalho, J-M., The regulation of tourism settlements in the Portuguese territory: tradeoffs and inefficiencies. Sustainable Development and Planning, 7, pp. 941-952, 2015. https://doi.org/10.2495/sdp150791

[3] DG Enterprise \& Industry, European Tourism Indicator System. Toolkit for sustainable destinations, European Union, Bruxelles, 2013 (on line).

[4] Cavaco, C., Turismo, desenvolvimento regional e local (Chapter). Geografia de Portugal: planeamento e ordenamento do território, dir. C. Medeiros, Círculos de Leitores e Autores: Lisboa, pp. 400-427, 2006.

[5] Hornillos, M. J., El Modelo Urbanizador "Resort” Análisis, Contexto Y Repercusiones En El Campo De Murcia Y Mar Menor. Universidad Politécnica de Cartagena, Cartagena: pp. 21-35, 2010 (online).

[6] Hayllar, B. \& Griffin, T., The precinct experience: a phenomenological approach. Tourism Management, 26, pp. 517-528, 2005.

https://doi.org/10.1016/j.tourman.2004.03.011 